perspectivas

a debate La eficiencia energética y la edificación histórica | coordinan Mónica López Sánchez, Ana Yáñez Vega

\title{
Entre preservación y mejora de la eficiencia energética de la edificación histórica
}

Emanuela Giancola | CIEMAT (Centro de Investigaciones Energéticas, Medioambientales y Tecnológicas), investigadora en la Unidad de Eficiencia Energética en la Edificación

URL de la contribución <www.iaph.es/revistaph/index.php/revistaph/article/view/3654>

Para lograr los objetivos definidos en el plan europeo sobre la eficiencia energética y la directiva 2012/27/UE relativa a las prestaciones energéticas de los edificios no será suficiente aumentar sólo el rendimiento de los nuevos edificios, sino también hay que centrarse en la rehabilitación de las edificaciones existentes, incluidas las históricas.

Una gran dificultad a la hora de relacionar eficiencia energética y patrimonio histórico se encuentra en el marco legislativo europeo, en el que no aparecen consideraciones, instrumentos jurídicos y aplicaciones específicas para estos edificios históricos. De hecho, se contemplan dos escenarios: uno que prevé para los edificios monumentales bajo protección una inmovilidad casi total derivada del uso simplista del instrumento "derogatio", que permite mantener la baja eficiencia energética de los edificios porque las medidas podrían generar "inaceptables alteraciones" del carácter y apariencia del edificio histórico; y otro que indica que los edificios históricos estén totalmente sujetos al cumplimiento de los estándares mínimos de rendimiento energético, particularmente restrictivos y ciertamente no fáciles de conseguir en los edificios antiguos.

El gran número de iniciativas internacionales que tienen como objetivo la mejora de la eficiencia energética de los edificios históricos son testigos de la importancia de definir una metodología común hacia soluciones tecnológicas innovadoras y materia histórica. La mayoría de los proyectos financiados en Europa finalizaron (o se finalizarán) con la elaboración de directrices que ayuden a los profesionales en intervenciones eficaces y al mismo tiempo respetuosas con el patrimonio. En presencia de edificios históricos, bajo protección o no, existe sin embargo el riesgo de proponer líneas de acción generales que, a pesar de que representen buenas prácticas, pueden no tener en cuenta el principio de "caso a caso", de vital importancia para la restauración de bienes que tienen sus propias características y peculiaridades en virtud de su valor histórico-cultural.

Cada edificio es una expresión de la época histórica en la que se realizó, del gusto, del arte de construir y del conocimiento técnico característico del contexto geográfico en el que se encuentra. La imperiosa necesidad de operar en el patrimonio arquitectónico existente, con el

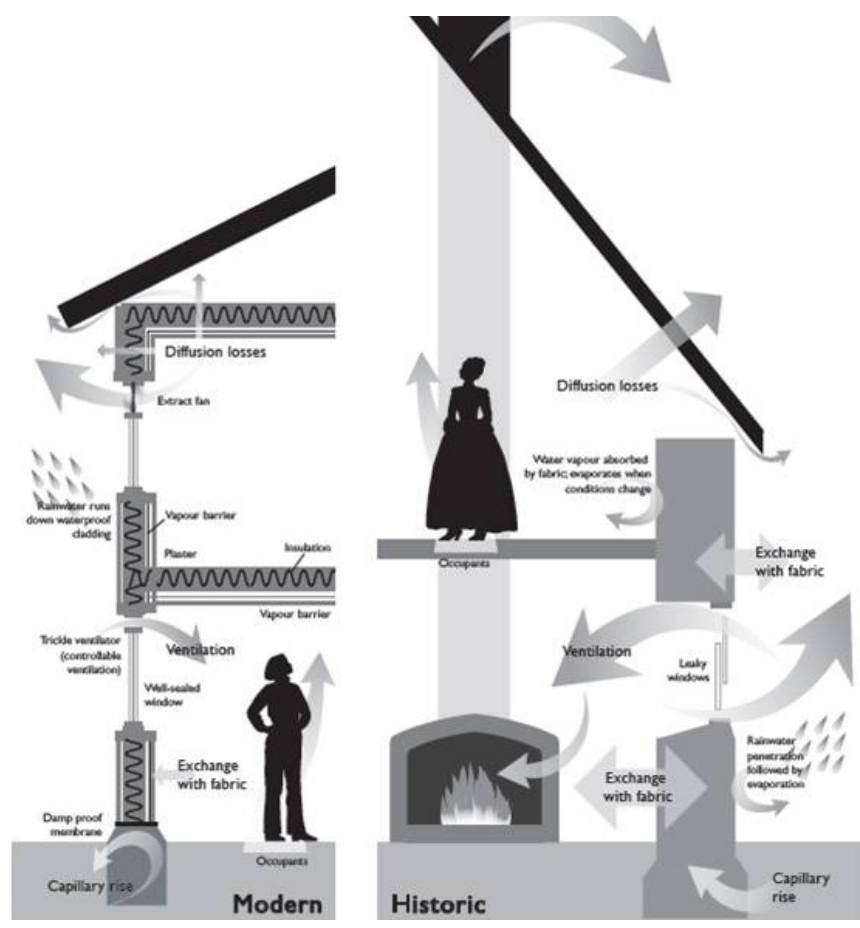

Control de la humedad. Ventilación | fuente ENERGY, 2011: 28 


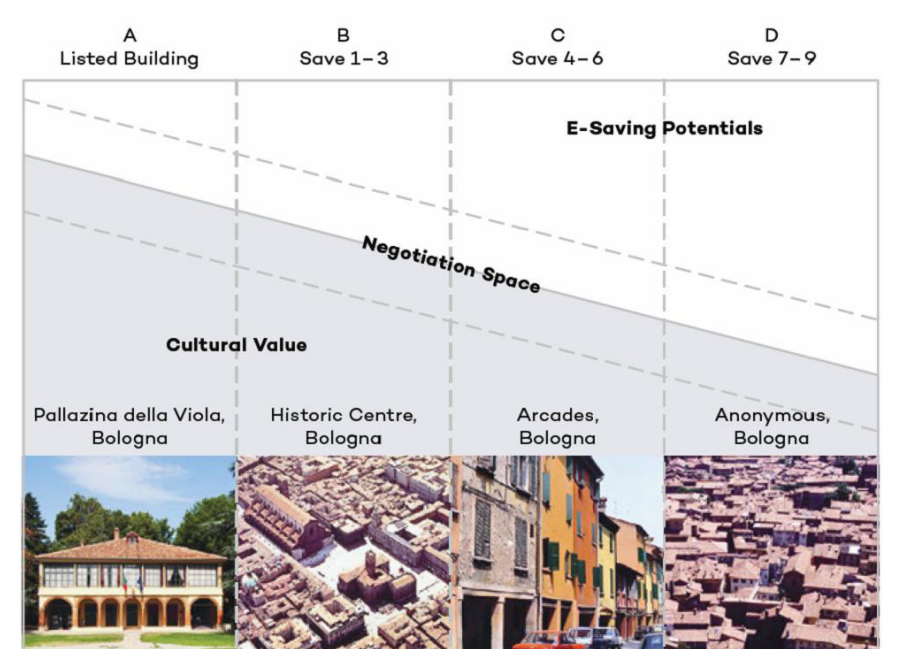

Cuatro categorías de valores culturales y arquitectónico | fuente TROI; BASTIAN, 2015: 87

objetivo de mejorar la eficiencia energética, nos pone ante un conflicto que se debate entre la observación de los principios propios de la restauración y los límites impuestos por la legislación relativa a la reducción del consumo energético.

Las operaciones de retrofit energético y la adopción de medidas para el uso eficiente de energía en los edificios históricos resultan más complejas, más caras y, a veces, menos eficaces que lo que se consigue en edificios de nueva construcción. Mientras que para el retrofit energético de los edificios posteriores a la Segunda Guerra Mundial, las prescripciones y los requisitos fueron claros, siendo relativamente fácil conseguir amplios márgenes de mejora en la eficiencia energética de fábricas estandarizadas, el camino para los edificios históricos está todavía relativamente inexplorado. De hecho, a este sector se añaden problemas provenientes tanto de la necesidad indispensable de comprender totalmente las diferentes características de cada edificio, actuando desde el pleno respeto de la materia histórica que lo caracteriza, como por la presencia de los múltiples valores de los que es testigo. Un problema es, por ejemplo, el cambio de uso, que también debe ajustarse a las limitaciones normativas. En presencia de bienes histórico-arquitectónicos, las opciones de proyecto están vinculadas además por las normas de protección, fundamentales para garantizar la "protección y conservación".

Las implicaciones económicas relacionadas con el cambio de uso de los bienes históricos generan una nueva confusión entre fines y medios de la restauración arquitectónica. La asignación de la función más apropiada para un bien es sin duda la forma más eficaz para su conservación; pero, por desgracia, es habitual considerar la reutilización como el objetivo final de la restauración. Sucede, de hecho, que la original configuración morfología-funcional del bien se sacrifica en favor de un nuevo uso no compatible, ya que igual está lejos de la función original del edificio y su distribución espacial. En el contexto económico y social actual una conveniente reutilización de los edificios históricos se convierte en un deber para reducir el consumo de energía y de suelo: "Lejos de ser un lujo para la comunidad, el uso del patrimonio es una fuente de economías" (CARTA, 1975, punto 3).

El problema que surge con frecuencia en este área es considerar el tema de la eficiencia energética con la mera inclusión de nuevos dispositivos y sistemas, a menudo dejando de lado los aspectos más relevantes para el ámbito de la protección; falta una mirada más amplia, especialmente necesaria de cara a políticas a largo plazo, que reconozca los valores culturales como recursos no renovables, para lo cual la preservación física se convierte en objetivo primordial en el proceso de salvaguardar el valor de autenticidad. El reto de la eficiencia energética del patrimonio histórico consiste precisamente en la identificación de una llave que combina dos mundos que son aparentemente distantes, y que en realidad están unidos por el objetivo compartido de la conservación de los recursos.

Para ello tenemos que promover un cambio de perspectiva que apunte a la idea de ahorrar recursos como un proceso único, dirigido a una comprensión global del sistema y elaborar proyectos de retrofit que sepan hablar y discutir con la multiplicidad de variables que intervienen en el juego. Por lo tanto se hace necesario definir 
criterios para lograr un balance energético equilibrado que permita alcanzar la mejor relación posible entre las tecnologías avanzadas, la naturaleza de la consistencia histórica y la identidad de lo "existente".

Es necesario que tanto la sostenibilidad como la práctica restaurativa converjan en una dirección, formando un nuevo marco ético, cultural y funcional coherente con las necesidades de la historia y también con los temas energéticos. Todo esto es posible sólo con la cooperación de las distintas partes interesadas, incluidos los ciudadanos, con el fin de lograr una gobernanza que, sobre la base de un escenario de referencia común, impulse la difusión de innovaciones logradas.

\section{BIBLIOGRAFÍA}

- BostenARU, M. (2004) Review of retrofit strategies decision system in historic perspective. Natural Hazards and Earth System Sciences, 4, 3, 2004, pp. 449-462

- CARTA europea del patrimonio arquitectónico. Ámsterdam, 1975

- DYRBOL, S.; THOMSEN, K. E.; ALNAEK, T. (2010) European Directive on the Energy Performance of Buildings: Energy Policies in Europe - Example of best practices [recurso disponible en línea]. ACEEE Summer Study on energy Efficiency in Buildings, August 2010. ACEEE, $2010<\mathrm{http}: / /$ aceee.org/files/proceedings/2010/data/papers/2155.pdf> [Consulta: 13/07/2015]

- ENERGY Efficiency and Historic Buildings: Application of Part $L$ of the Building Regulations to historic and traditionally constructed buildings (2011) Londres: English Heritage, 2011

- KAKLAUSKAS, A.; KAZIMIERAS ZAVADSKAS, E.; BIRUTE, G. (2008) A building's refurbishment knowledge-based decision support system. International Journal of Environment and Pollution, Vol. 35, 2/3/4, 2008, pp. 237- 249

- RESPONSIBLE Retrofit of Traditional Buildings (2012) [en línea] London: STBA, 2012 <http://www.spab.org.uk/ downloads/STBA\%20RESPONSIBLE-RETROFIT.pdf> [Consulta: 13/07/2015]

- TROI, A.; BASTIAN, Z. (2015) Energy Efficiency solution for Historic Buildings, A handbook. Basel: Birkhäuser Verlag Gmbh, 2015 